\title{
Liquid limits and fall cones: Discussion
}

A Sridharan; K Prakash

Canadian Geotechnical Journal; Apr 1998; 35, 2; ProQuest Science Journals pg. 407

The authors have compared the liquid limit values obtained by the percussion method and the fall cone method and also compared the values obtained by the methods and standards followed in different countries. In this connection, the discussers would like to comment on certain issues.

The details pertaining to the Indian cone given in Table 1 of the note do not tally with the method that is currently being adopted in India. The Indian code of practice for the determination of liquid and plastic limits when first published in 1965 contained only the percussion method. In the first revision in 1970 , the cone method of determining the liquid limit was introduced, which contained the details given in Table 1 of the note. The second revision of the code was done in 1985, and currently, the same revised version is being adopted (IS: 2720-Part 5 (Bureau of Indian Standards 1985)). According to this, the cone has an apex angle of $30 \pm 1 / 2^{\circ}$, a length of $35 \mathrm{~mm}$, and a mass of $80 \pm 0.5 \mathrm{~g}$. The liquid limit is the moisture content corresponding to a $20 \mathrm{~mm}$ penetration of the cone. The Indian code also identifies a one-point method of determining the liquid limit using the cone and gives two equations:

$$
\begin{aligned}
& \text { [D1] } w_{\mathrm{L}}=\frac{w_{\mathrm{N}}}{0.77 \log D} \\
& \text { [D2] } w_{\mathrm{L}}=\frac{w_{\mathrm{N}}}{0.65+0.0175 D}
\end{aligned}
$$

where $w_{\mathrm{N}}$ is the water content corresponding to a penetration of $D \mathrm{~mm}(16 \mathrm{~mm}<D<26 \mathrm{~mm})$.

Many investigators have tried to compare the liquid limits obtained by the percussion method as per BS-ASTM (British standard adopts a soft based and ASTM standard specifies a hard base) with those obtained by the cone method (Sherwood and Ryley 1970; Skopek and Ter-Stepanian 1975; Littleton and Farmilo 1977; Budhu 1985; Moon and White 1985; Queiroz de Carvalho 1985; Sivapullaiah and Sridharan 1985; Wasti and Bezirci 1986; and Rao 1987, to name a few). It has been observed by many, including the discussers, that the liquid limit obtained by the percussion method can be as low as about $26 \%$ less than and as high as about $71 \%$ more than the liquid limit obtained by the cone method. However, no attempt has been made in the past to recognize the cause for this difference, except for Budhu (1985) who has attributed the observed dif-

Received August 20, 1997. Accepted November 19, 1997.

A. Sridharan and K. Prakash. Indian Institute of Science, Bangalore 560012 , India.

I Paper by S. Leroueil and J.-P. Le Bihan. 1996. Canadian Geotechnical Journal, 33: 793-798.
Fig. D1. Comparison between the liquid limits obtained from the percussion method and the cone method.

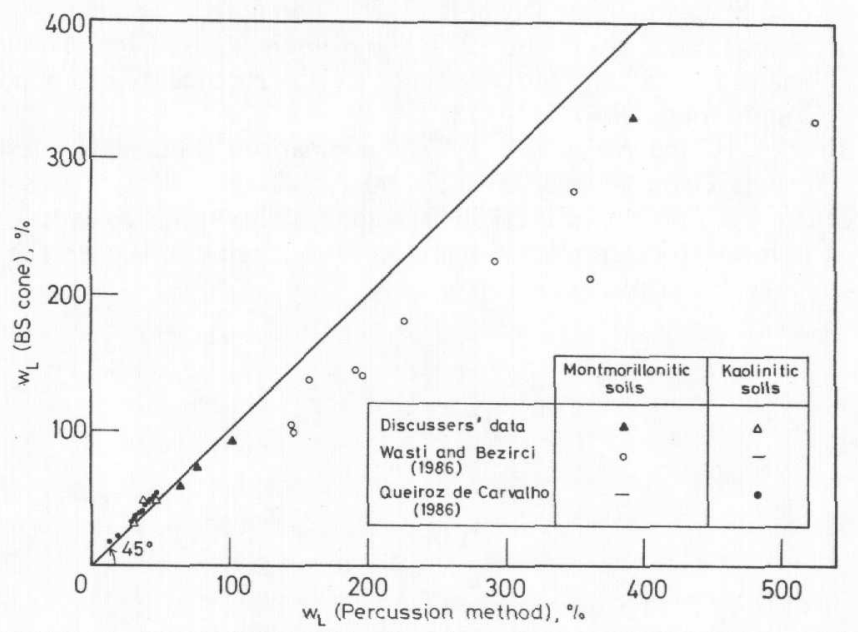

ference in the results by the two methods to the clay content of the soil.

The first discusser has been involved in many research works in the past concerned with the mechanisms governing the liquid limit of soils (Sridharan and Venkatappa; Rao 1975; Sridharan et al. 1986; Sridharan et al. 1988; Sridharan 1991). These works have indicated that the mechanisms controlling the liquid limit of the kaolinitic soils and montmorillonitic soils are different. While the mode of particle arrangement as governed by the interparticle forces controls the liquid limit of kaolinitic soils, the thickness of the diffuse double layer controls the liquid limit of montmorillonitic soils.

Figure D1 shows a typical comparison of the liquid limits obtained by the British Standard cone method with those obtained by the percussion method. The data presented include only those soils in which the dominant clay mineral type present is known. The data of Queiroz de Carvalho (1986) correspond to lateritic soils from Brazil, which contain kaolinite as the only clay mineral. For those soils, the cone method gave higher values than the percussion method. The soils tested by Wasti and Bezirci (1986) are montmorillonite-rich soils (i.e., mixture of bentonite and natural soils from Turkey). For all the soil mixtures tested, the percussion method gave much higher values than the cone method. The discussers' data in Fig. D1 correspond to natural soils. They have observed that the cone method gives a higher liquid limit than the percussion method for kaolinitic soils and that the percussion method results always give higher liquid limits than the cone method for montmorillonitic soils. 
In the light of the above discussion, the discussers are of the opinion that the dominant clay mineral type and its proportion in the clay content are responsible for the deviations between the results obtained from the percussion and cone methods, rather than the clay content alone as proposed by Budhu (1985).

\section{References}

Budhu, M. 1985. The effect of clay content on liquid limit from a fall cone and the British cup device. Geotechnical Testing Journal, 8(2): 91-95.

Bureau of Indian Standards. 1985. Indian standard: methods of test for soils. Determination of liquid and plastic limit. Bureau of Indian Standards, New Delhi, IS: 2720-Part 5.

Littleton, I., and Farmilo, M. 1977. Some observations on liquid limit values with reference to penetration and Casagrande tests. Ground Engineering, 10(4): 111-118.

Moon, C.F., and White, K.B. 1985. A comparison of liquid limit test results. Géotechnique, 35(1): 59-60.

Queiroz de Carvalho, J.B. 1986. The applicability of the cone penetrometer to determine the liquid limit of lateritic soils. Géotechnique, 36(1): 109-111.
Rao, H.Y. 1987. Proceedings, 8th Asian Regional Conference on Soil Mechanics and Foundation Engineering, Kyoto, Japan, Vol. 1, pp. 81-84.

Sherwood, P.T., and Ryley, M.D. 1970. An investigation of a conepenetrometer method for the determination of the liquid limit. Géotechnique, 20(2): 203-208.

Sivapullaiah, P.V., and Sridharan, A. 1985. Liquid limit of soil mixtures. Geotechnical Testing Journal, 8(3): 111-116.

Skopek, J., and Ter-Stepanian, G. 1975. Comparison of liquid limit values determined according to Casagrande and Vasilev. Géotechnique, 25(1): 135-136.

Sridharan, A. 1991. Engineering behaviour of fine grained soils - A fundamental approach. Indian Geotechnical Journal, 21(1): $1-136$.

Sridharan, A., and Venkatappa Rao, G. 1975. Mechanisms controlling the liquid limit of clays. Proceedings, Conference on Soil Mechanics and Foundation Engineering, Istanbul, Vol. 1: 65-74.

Sridharan, A., Rao, S.M., and Murthy, N.S. 1986. Liquid limit of montmorillonite soils, Geotechnical Testing Journal, 9(3): 156-159.

Sridharan, A., Rao, S.M., and Murthy, N.S. 1988. Liquid limit of kaolinitic soils. Géotechnique, 38(2): 191-198.

Wasti, Y., and Bezirci, M.H. 1986. Determination of the consistency limits of soils by the fall cone test. Canadian Geotechnical Journal, 23(2): 241-246.

\section{Liquid limits and fall cones: Reply'}

\section{Serge Leroueil and Jean-Pierre Le Bihan}

The Authors are grateful for the interest that the Discussers have shown in this paper.

The Discussers present a comparison of liquid limits obtained by the percussion method with those obtained by the fall cone method. Typically, the percussion method gives higher liquid limit values than the fall cone method for liquid limits higher than about $60 \%$, and lower values when the liquid limit is lower than about $60 \%$. They indicate that the difference depends on the dominant clay mineral type. This is certainly an important factor, but probably not the only one, since the Authors found a similar behaviour (Figs. 3 and 5) with clayey soils from eastern Canada having essentially the same dominant clay minerals.
The Discussers also give details concerning the fall cone method currently used in India. It may be of interest to mention that a recent paper by Farrell et al. (1997) confirms the Authors' observation (Fig. 1) that the liquid limit determined with the $60^{\circ}-60 \mathrm{~g}$ fall cone at a depth of penetration of $10 \mathrm{~mm}$ is practically equal to that determined with the $30^{\circ}-80 \mathrm{~g}$ fall cone at a depth of penetration of $20 \mathrm{~mm}$.

\section{Reference}

Farrell, E., Schuppener, B., and Wassing, B. 1997. ETC 5 fall-cone study. Ground Engineering, 30(1), 33-36.

Received November 12, 1997. Accepted November 19,1997.

S. Leroueil. Département de génie civil, Cité universitaire, Université Laval, QC GIK 7P4, Canada.

J.-P. Le Bihan. St-Valérien, QC JOH 2B0, Canada.

${ }^{\prime}$ Discussion by A. Sridharan and K. Prakash. This issue. Canadian Geotechnical Journal, 35: 407-408. 